Síntese: Revista de Filosofia adere a uma Licença

\title{
O EXERCÍCIO DA MORTE (MELÉTE THANÁTOU) NO PRAKTIKÓS DE EVÁGRIO PÔNTICO *
}

The exercise of death in the Praktikós of Evagrius Ponticus

Marcus Reis Pinheiro **

Resumo: Neste artigo, apresentaremos alguns aspectos do exercício da morte (meléte thanátou) ou lembrança da morte (mnéme thanátou) em Evágrio Pôntico (346d.c.-400d.c.), traduzindo e comentando dois capítulos do Praktikós, o 29 e o 52. Tal exercício tem como locus clássicus o diálogo platônico em que Sócrates encontra seu fim, o Fédon $(63 \mathrm{~b}-69 \mathrm{e} ; 80 \mathrm{e}-81 \mathrm{a})$. Assim, tendo como horizonte suas características neste diálogo, o presente artigo analisa os textos de Evágrio indicando torções, inovações e continuidades frente ao texto platônico. $\mathrm{O}$ roteiro que seguiremos será primeiro (1) uma apresentação sumária do modo como o exercício aparece no Fédon, depois, (2) uma rápida visão geral dos textos ascéticos dos inicios do monasticismo cristão (especialmente como ele aparece na Vida de Santo Antão, de Atanásio), para por fim, (3) analisar os textos de Evágrio mencionados. Podemos perceber ao longo da pesquisa uma distinção clara entre Platão e Evágrio: os aspectos epistêmicos, centrais no Fédon, não estão presentes nos textos de Evágrio indicados acima. Na medida em que o exercício da morte se vincula à parte prática da obra de Evágrio, os assuntos epistêmicos são pouco centrais na descrição do exercício em questão, mesmo que o télos de toda ascese seja algum tipo de conhecimento, a gnósis. Há ainda outra diferença importante, apesar de secundária. Além disso, nos textos de Evágrio analisados, o exercício

* Artigo recebido em 13/01/2020 e aprovado para publicação em 28/07/2020.

** Doutor e Pós-doutor em filosofia pela PUC-Rio. Professor Associado do departamento e do programa de pós-graduação de Filosofia da Universidade Federal Fluminense. 
da morte é também um exercício de imaginação que leva à urgência para com a ascese: Em Evágrio, deve-se ter em mente uma possível proximidade da morte para que a vida excelente seja vivida urgentemente.

Palavras-chave: Exercício da morte. Evágrio Pôntico. Fédon. Platão. Monasticismo.

Abstract: This paper presents some aspects of the exercise of death (meléte thanátou) or memory of death (mnéme thanátou) in Evagrius Ponticus (346, - 400 AD.) through the translation and commentary of chapters 29 and 52 of the Praktikós. The locus classicus of this exercise of death is the Phaedo $(63 \mathrm{~b}-69 \mathrm{e}$ and $80 \mathrm{e}-81 \mathrm{a})$, the platonic dialogue in which Socrates meets his end. Based on the dialogue characteristics, the paper analyses Evagrius Ponticus' texts showing the twists and turns, innovations, and continuities in comparison to the Platonic dialogue. Our approach will first (1) briefly describe the way in which the exercise is presented in the Phaedo, (2) give a quick overview of the ascetic texts of early Christian monasticism (especially how it appears in Athanasius 'Life of Saint Antony by Athanasius), and, lastly, (3) examine the Evagrian texts mentioned above. Throughout the research, a clear distinction was drawn between Plato and Evagrius: the epistemic aspects, central to the Phaedo, are absent from the Evagrian texts discussed. As the exercise of death is linked to the practical part of Evagrius' work, the epistemic issues are not at central to the description of the exercise in question. Though it is secondary, another important difference is that in Evagrius' texts, the exercise of death is also an exercise of imagination which leads to an urge to asceticism. For Evagrius, it is only possible to lead an excellent life if one bears in mind the proximity to death.

Keywords: Exercise of death. Evagrius Ponticus. Phaedo. Plato. Monasticism.

\section{Introdução}

1 este artigo, apresentaremos alguns aspectos do exercício da morte (meléte thanátou) ou lembrança da morte (mnéme thanátou) em Evágrio Pôntico (346d.c.-400d.c.) como ele aparece em dois capítulos do Praktikós ${ }^{1}$, o 29 e 52. Tal exercício tem como locus clássicus o diálogo platônico em que Sócrates encontra seu fim, o Fédon (63b -69e; 80e-81a). Assim, tendo como horizonte suas características neste diálogo, o presente artigo analisa os textos de Evágrio indicando torções, inovações e continuidades frente ao texto platônico. $\mathrm{O}$ roteiro que seguiremos será primeiro (1) uma apresentação sumária do modo como o exercício aparece no Fédon, depois (2), uma rápida visão geral dos textos ascéticos

\footnotetext{
${ }^{1}$ EVAGRIUS. Praktikós. Traité Pratique ou Le Moine. Traduzido e comentado por Antoine e Claire Guillaumont. Sources Chrétiennes n. 170 e 171. Paris: CERF, 1971. O primeiro volume, o n. 170 é só uma grande introdução dos tradutores. O segundo, n. 171, é a tradução com extensos comentários.
} 
dos inicios do monasticismo cristão (especialmente como ele aparece na Vida de Santo Antão, de Atanásio), para por fim (3), analisar os textos de Evágrio mencionados.

Ainda como apresentação geral do que vai ser discutido aqui, gostaria de apresentar três modos de se compreender o exercício da morte, lembrando que tais modos de compreensão podem se sobrepor ou se distanciar. São eles: 1. a prática diária de afastar-se dos cuidados corpóreas, desprezando os apelos do desejo corporal; 2. exercício de imaginação da vida post mortem (levando em conta a alma individual); 3. exercício de imaginação da iminência da morte, gerando o páthos ${ }^{2}$ da iminência ou o páthos da urgência. Haveria, ainda, um $4^{\circ}$ modo, o exercício de imaginação do fim de todos os tempos, promovendo uma perspectiva escatológica que, apesar de não aparecer no Fédon, será largamente utilizado na literatura monástica ${ }^{3}$.

Podemos encontrar esses três aspectos nos diferentes textos que iremos analisar aqui e uma descrição mais pormenorizada será feita no momento adequado. Vale frisar, como apresentação geral, que acredito podermos encontrar no Fédon mais claramente os aspectos 1 e 2 (a prática diária e o exercício do post-mortem), e muito menos o 3 (o exercício da urgência), sendo, no entanto, complexa a relação destes aspectos tanto ao longo do Fédon quanto nos outros textos aqui apresentados.

\section{Exercicio da morte no Fédon de Platão}

O diálogo Fédon como um todo é um grande tratado sobre a morte em que o tema se repercute no diálogo em diversos níveis. Nele, podemos encontrar tanto a descrição factual da morte de Sócrates (como apresentada por Platão), quanto argumentos que buscam provar a imortalidade da alma, quanto uma descrição do post mortem, como também a prática do exercício da morte identificada à própria filosofia. Obviamente, é importante lembrar que o que se chama de exercício da morte está inserido em um diálogo que visa tanto a defender a nobreza com o qual Sócrates enfrentou a própria morte (uma espécie de apologia dramática de Sócrates),

\footnotetext{
${ }^{2} \mathrm{O}$ termo páthos aqui é ainda uma experimentação, já que o termo, de modo geral tem um teor negativo em Evágrio. No entanto acredito que seja pertinente se pensar em uma emoção específica que configura o estado psíquico a ser analisado mais à frente.

${ }^{3}$ Tal aspecto do exercício da morte pode ser percebido nos apoftegmas III,2 e III,5, em que há um imperativo de, ao se sentar em sua cela, lembrar-se da morte visualizando as consequências boas para os bons e ruins para os ruins no dia do juízo final. Um excelente livro sobre os sentidos da morte na tradição filosófica, bíblica e monástica é o de Zecher, J. L. The role of death in the Ladder of Divine Ascent and the Greek Ascetic Tradition. Oxford: Oxford University Press, 2015.
} 
quanto a apresentar argumentos e mitos sobre a eternidade da alma e o seu destino post mortem. Todo o diálogo tem o objetivo de convencer os espectadores ${ }^{4}$ (e por extensão, seus leitores) que a atitude corajosa e até mesmo alegre de Sócrates perante a morte é digna e consistente e, por conseguinte, convencê-los a também ter coragem ao encarar a própria morte, na medida em que seu discurso insufla de esperança aquele que está em vias de morrer (em verdade, todos nós). Assim, em certo sentido, o texto é menos uma investigação propriamente teórica da morte, termo que remete simplesmente ao fim da vida, mas uma apologia (defesa) da vida filosófica enquanto exercício da morte como purificação da alma em que ela é preparada para o acontecimento inevitável da morte. Vejamos isto com calma.

Como já dito, nos concentraremos nas passagens em que explicitamente Sócrates descreve o exercício da morte. Este exercício é apresentado como a própria definição da filosofia e descreve uma atitude geral do filósofo que se manifesta em diversos aspectos de sua vida. Por um lado, pode parecer que tal exercício se remeta a uma preparação para a morte, como se ele nos preparasse para um evento que ainda não ocorreu. Tal forma de compreender o exercício sublinha o aspecto de que seria necessário se preparar para a morte no sentido de não lhe ter medo, ganhando assim uma atitude virtuosa perante algo que só acontecerá no fim da vida. Neste sentido, tal exercício possibilitaria uma coragem específica em relação a ela e nos fortificaria para determinadas decisões em que a morte estaria envolvida: na medida em que a morte possa ser uma barganha frente à virtude, por exemplo, o filósofo escolheria a vida virtuosa e permaneceria virtuoso mesmo tendo que morrer. Apesar de este sentido também ser encontrado no Fédon, o que ali é descrito é mais radical. Os termos usados melétao (67e; 80e-81a) e epitẹdeúo (64a) não são propriamente relacionados a uma preparação, isto é, uma atividade prévia, mas sim a um exercício, a um exercitar-se na morte em vida. O modo como tal exercício é descrito nos remete para uma prática diária que efetiva em certo grau aquilo que ocorrerá no momento da morte propriamente, ao termino (desta) vida. Em 67e, Sócrates nos diz que o filósofo se prepara a vida toda para estar no estado em que o morto está, indicando assim uma prática concreta de viver como se estivesse morto e não viver se preparando para a morte como se fosse algo distinto do que ele realiza em vida. O exercício da morte no Fédon tem o sentido de um exercer a morte, exercitar-se em "morrer e em estar morto" (epitedeúousin [...] apothnéskein te kaì tethnánai 64a), isto é, praticar o ato próprio do morrer que é "separar a alma do corpo" (tè $n$ tệs psykhèes apò tô̂ sómatos apallagèn $64 \mathrm{c}$ ).

\footnotetext{
${ }^{4}$ Em 63b temos: “ [...] que é necessário defender-me (apologésasthai) perante vocês como em um tribunal (dikasteríoi) [...] Em 63 e, Sócrates chama seus interlocutores de juízes (tô̂s diakstaîs) e também em 69 d [...] defendo-me [...] (apologoûmai).
} 
Esta prática do morrer em vida tem diversos níveis e gostaria de sublinhar pelo menos três deles. A princípio, não se trata, exatamente, de um exercício imaginativo ${ }^{5}$ (como veremos mais à frente em Evágrio) em que certos aspectos da morte são rememorados e imaginados como forma de produção de uma vida virtuosa ou de uma preparação para a morte concreta, quando ela vier. Esta separação remete tanto a (1) aspectos propriamente ascéticos - desprezar (atimázei) comida, bebida, adereços e roupas - quanto (2) a aspectos éticos - produzir virtude na alma do filósofo a partir de uma kátharsis - quanto a (3) aspectos epistemológicos - ao propiciar a alma, sozinha por si mesma, contemplar as realidades que também existem por si sós. Em uma forma sintética, podemos dizer que se trata de (1) uma fuga do corpo e de todos os problemas a ele atrelados e que esta fuga é uma forma de (2) purificação que produz virtudes, sendo que a alma (3) se acostuma a se recolher sobre si mesma, buscando somente seus próprios instrumentos - o pensar (dianoeisthai) - para encontrar o seu desejo mais profundo, a sophia. Vamos a uma breve análise destes três aspectos.

Primeiramente, (1) o filósofo é apresentado como alguém que ao se interessar pela verdade, não se preocupa (espoudakenai 64d) com os prazeres de comer e beber, assim como os de Afrodite, e também com objetos para o corpo, como roupas e sandálias, sendo que ele despreza (atimázei) esses na medida em que não é necessário utilizá-los. Sobre este primeiro nível, ao comparar com a ascese típica monástica, me parece interessante ressaltar que o grau de aceitação dos elementos desta espécie é bem mais palatável em Platão que no monasticismo. Não se pode imaginar o Fédon propondo uma dieta magra e austera como os monges a experimentaram. O que se sublinha é mais da ordem de um desprezo, de um não se importar, apoiando-se no fato de que o interesse e o desejo ${ }^{6}$ do filósofo se volta para os assuntos psíquicos. Assim, afastar-se dos cuidados (therapeía) do corpo é um impulso filosófico na medida em que o filósofo é marcado pelo desejo da verdade. O filósofo não é um inimigo dos prazeres do corpo, ele simplesmente os acha pouco interessantes, pouco estimulantes, e lida com eles na medida em que deles necessita para sobreviver. Ele não tem apego aos cuidados do corpo, mas realiza o estritamente necessário, mesmo que o limite deste necessário não esteja explícito no diálogo. A vida monástica, que vivia com uma redução drástica destes cuidados, não parece exatamente implícita neste exercitar-se em afastar seus cuidados do corpo. Assim, mesmo o diálogo Fédon sendo central para a tradição das atividades ascéticas cristãs, há uma diferença bem radical na dose, digamos assim, de desprezo pelos cuidados com o corpo.

\footnotetext{
${ }^{5}$ É verdade que pode-se pensar o mito escatológico do final do Fédon (107d-115c) como um exercício imaginativo, que impulsiona determinadas afecções e nos exige e treina para sermos virtuosos.

${ }^{6}$ Sobre o léxico do desejo no Fédon, ver as passagens 65 c orégetai, 66d hoû epithymoûmen, 66e érastai.
} 
Há, ainda a relação intrínseca entre (3) os aspectos epistemológicos deste exercício e a (2) produção de virtudes. A atividade própria deste exercício da morte é um recolher-se (83a athroizesthai e xyllégesthai) da alma sobre si mesma, afastando-se do corpo e da aísthesis, para acessar as realidades em si através da pura intelecção (diánoia eilikrineîn). Este recolher-se está intimamente conectado com uma forma de purificação própria para a produção das virtudes. Nesta relação entre virtudes e epistéme estão presentes tanto o linguajar da purificação (kátharsis) típica dos mistérios (tàs teletás) quanto o linguajar da homoíosis theôi, assemelhar-se ao deus. A alma, ao afastar-se do corpo e tornar-se pura, permanecendo ela mesma, em si mesma, consigo mesma, torna-se semelhante aos objetos que deve conhecer, as realidades elas mesmas em si mesmas por si mesmas (83d noései auté kath'autè̀n autó kath'hautò tộn óntonn). Essa semelhança entre aquele que conhece e o que é conhecido está na mesma linha de argumentação do tornar-se do génos dos deuses, morar com eles (69c), e é parte do topos da homoíosis theôi tão famosa pelo Teeteto ${ }^{7}$.

O personagem Sócrates ainda aponta para um aspecto post-mortem deste exercer a morte, já que o processo de afastar-se do corpo é um processo de purificação (kátharsis) da alma para que após a morte ela vá pura viver junto aos deuses e não deite na lama do Hades (Haídou, en borbóroi i). Todo o linguajar típico dos mistérios é retomado e há, mesmo que pouco sublinhado, certa imaginação ativa sobre os destinos da alma depois da morte. Os filósofos, que praticam essa forma de morrer em vida, são aqueles iniciados nos mistérios (bákkhoi), em comparação aos muitos que não são (thýrsoi).

\section{Exercício da morte na Vida de Santo Antão de Atanásio}

É notório que a influência deste exercício vai além da Grécia clássica e se desenvolve exemplarmente nas escolas helenísticas, especialmente a epicurista, a estoica e a de tradição neoplatônica. Tal influência vai além mesmo da filosofia grega, estando presente em importantes autores como Clemente de Alexandria (Stromates V, 11, 67), Gregorio de Nazianzo (Discursos Teológicos I, 7 e Carta 31) e Máximo Confessor (Comentário ao Pai Nosso).

Desde o início dos movimentos cristãos, se tem consciência das rupturas, transposições e continuidades de conceitos e práticas gregos. Pode-se traçar alguns aspectos de continuidade e distinções entre o meléte thanátou em Platão e nos inicios do monasticismo. Sendo em Platão a própria definição do fazer filosófico, ao chegarmos na primeira literatura monástica, o exer-

\footnotetext{
${ }^{7}$ Ver Teeteto 175e-176b. Sobre esse tema, ver também Leis IV 687d-688b; República 613b e Timeu 90d.
} 
cício da morte ganha um papel central na ascese dos padres do deserto dos séculos IV e V d.c., adquirindo tons claramente inovadores frente ao mundo helênico, especialmente no que concerne o aspecto escatológico e post-mortem. O objetivo do restante deste artigo, como já foi dito, é sublinhar alguns traços deste exercício em algumas passagens de alguns textos monásticos vinculados ao nome de Evágrio Pôntico.

De modo a situar minimamente o leitor nos textos de Evágrio a serem analisados, algumas palavras sobre o monasticismo dos séculos IV e V d.c., em especial sobre o exercício da morte ali presente. Podemos situar os inicios do movimento monástico em meados do século III d.c. ${ }^{8}$, mas é nos dois séculos seguintes que este movimento ganha uma força social e política incomparáveis. Por volta de 400 d.c, temos mosteiros com dois a três mil homens (e outros, menores, de mulheres) no deserto do Egito, vinculados a pelo menos três regiões principais: as kellai, ou Celas, Nítria e Scetis. Essas regiões formam os centros principais de organização dos cenóbios, organizações pré-monásticas em que os anacoretas viviam vidas totalmente isoladas, ou semi-isoladas ou em conjunto. Uma vasta literatura ${ }^{9}$ surgiu ao redor destes monges que retrata tanto sua vida cotidiana quanto os desafios e superações das suas práticas ascéticas. Esta literatura ascética tem uma função educativa nos meios destes primeiros mosteiros e a partir deles podemos derivar um conhecimento enorme tanto das teorias que motivavam a ascese quanto das práticas propriamente diárias.

Uma vida típica de um monge era composta basicamente de trabalho manual e oração ${ }^{10}$. Este trabalho consistia muitas vezes em trançar cordas para se fazer cestas que eram comercializadas para se comprar o sustento diário dos monges: um pedaço de pão duro umedecido para ser comido com um pouco de água. Há um conjunto de variações neste estilo de vida, como alguns monges plantando verduras e cozinhando-as ${ }^{11}$. O exercício manual está intimamente ligado à possibilidade de se praticar uma oração silenciosa enquanto se trabalha: recitar textos decorados, muitos vindo das escrituras. Havia, ainda, um encontro semanal, a sýnaxis, em que os monges se reuniam e realizavam uma refeição em comum.

Deve-se ressaltar que a vida retirada, a anacorese, compreendia um comércio e uma mobilidade relativamente grandes. Os monges, em sua maioria,

\footnotetext{
${ }^{8}$ Para uma excelente introdução aos inícios do movimento monástico, ver MARAVAL, P. "Le monaschisme oriental". In : PIETRI, C. \& PIETRI, P. Histoire du christianisme: des origines à nos jours. Naissance d'une chrétienté. Vol 2. Paris : Desclée, 1995.

${ }^{9}$ Podemos listar alguns como exemplo, mas a lista é muito vasta: Historia Monachorum, História Lausicaa, os Apophtegmata com as organizações Sistemática, Alfabética e Anônima, com todas suas versões e transformações, os textos vinculados a Pacômio, a Antão, a Doroteus de Gaza, a Filocalia, os textos de Evágrio e de Cassiano, etc.

${ }^{10}$ Ver AP (alf) Antão I, em que o anjo mostra para Antão o imperativo do ora et labora.

${ }^{11}$ Para a vida cotidiana dos monges, ver REGNAULT, L. The day to day life of the desert fathers in the fourth century Egypt. Massachusetts: St. Bede's Publication, 1999.
} 
viajavam e conversavam, tanto para trocar suas mercadorias, quanto para procurar algum mestre com quem se consultar. Assim, não se pode tratar a vida cenobítica destes séculos como sendo de uma ausência radical de trocas sociais ou mercantis, mas deve-se levar em conta a importância desta mobilidade ${ }^{12}$.

Podemos distinguir primeiramente, dois tipos de monges: o anacoreta, que vive de modo totalmente isolado e o cenobita (koinóbion, vida em comum), monge que vive em comunidades, sendo que há todo um mosaico de gradações entre uma vida completamente isolada e a vida comunitária do cenóbio. Se por um lado Pacômio é o fundador desta vida em comum, isto é, da vida do cenóbio, Antão é o herói paradigmático do anacoreta. Em verdade, a vida anacorética é o modelo para a vida cenobítica, sendo Antão o herói por excelência do movimento monástico.

Vale ressaltar que a bibliografia sobre a morte e sua relação com o monasticismo primitivo é muito vasta ${ }^{13}$, sendo que aqui não cabe analisar com cuidado diversas obras. No entanto, acredito ser pertinente descrever de modo sumario o modo como tal exercício se apresenta no que concerne à vida de Antão, especialmente por ser ele paradigmático para esses primeiros séculos de monasticismo. Muito desta popularidade de Antão se deve ao sucesso da hagiografia feita por Atanásio, A vida de Santo Antão. Nela, encontramos pelo menos três importantes passagens que remetem diretamente a um tipo de exercício da morte, o capítulo 19, o 89 e o $91^{14}$, sendo estes dois últimos vinculados à própria morte de Antão. No capítulo 19, 2 - 5, Atanasio nos diz o seguinte sobre o que Antão pensava ${ }^{15}$ :

2. Para não sermos negligentes, é bom exercitar a fala do Apóstolo: morro a cada dia. Se também nós vivermos como se morrêssemos a cada dia, não haveremos de pecar. 3. Isso foi dito para que, ao acordar a cada manhã, consideremos que não estaremos aqui à noite e, indo novamente dormir, consideremos que não acordaremos, porque nossa vida é por natureza incerta e medida a cada dia pela Providência. 4. Estando com essa disposição e vivendo desse modo todos os dias, não pecaremos, não teremos desejo de nada nem nos irritaremos com ninguém e tampouco acumularemos tesouros sobre a terra (cf. Mt 6, 19), mas, como se a cada dia esperássemos morrer, ficaremos sem propriedades e perdoaremos tudo a todos. 5. Não teremos absolutamente nenhum desejo de mulher ou de outro prazer sujo, mas dare-

\footnotetext{
${ }^{12}$ Sobre a mobilidade no monasticismo, ver por exemplo, DIETZ, M. Wandering Monks, Virgins and Pilgrims. Ascetic travel in mediterranean World, 300-800. Philadelphia: Pensilvania State University, 2005.

${ }^{13}$ Ver especialmente, ZECHER, J. L. The Role of Death in the Ladder of Divine Ascent and the Greek Ascetic Tradition. Oxford: Oxford University Press, 2015 e a extensa bibliografia ali presente. ${ }^{14}$ Poderíamos desenvolver um pouco as imagens apresentadas em 89 e 91 do Vida de Santo Antão, mas não é o caso aqui. Volta-se a repetir ali o imperativo de lembrar-se da morte todos os dias emoldurado pela própria morte do herói. No 91 há uma lista de conselhos e o lembrar-se da morte todos os dias está lá.

15 Tradução de Bruno Gripp, 2019.
} 
mos as costas para isso como se fosse coisa passageira, sempre combatendo e olhando para o dia do julgamento. Pois sempre o maior temor e o medo dos tormentos acabam com a moleza do prazer e despertam a alma desviante.

Assim, de acordo com Atanásio, Antão recomendava a meditação (meléte na palavra de Paulo "morro a cada dia" (1 Cor 15,31, kath'heméran apothnéskô). Interessante ressaltar que a meditação aqui é sobre a palavra (rhetón) de Paulo, que por sua vez é interpretada como um lembrar-se da morte. Temos uma primeira torção na medida em que o lembrar-se da morte passa por um lembrar a palavra que nos diz para nos lembrar da morte.

A partir disto, Antão propõe que, todo dia ao se levantar, o monge pense que hoje será o dia de sua morte e reaja ao viver como se a morte estivesse iminente, com o objetivo de não pecar. Uma argumentação interessante relaciona a imprevisibilidade da morte com o imperativo de lembrá-la. $\mathrm{Na}$ medida em que a providência é desconhecida, iremos, certamente, errar muitos dias, pois não será naquele exato dia que morreremos. Contudo, haverá necessariamente um dos dias em que esse pensamento exercitado será correto, apesar de nunca sabermos quando será. Fica a verdade: ao me propor o pensamento de que hoje seja o dia em que morrerei, pelo menos um dia acertarei.

Assim, o exercício da morte nesta passagem evoca tanto o fato da mortalidade e do inesperado do dia da morte, quanto a sua proximidade. Trata-se, diferentemente do Fédon, de procurar exercer uma perspectiva da proximidade da finitude ${ }^{16}$. Essa perspectiva é composta pela expectativa do fim próximo, configurando um estado de espirito que insufla o sujeito com força e argumentos a viver uma vida de virtude intensa. Gostaria de nomear essa expectativa de páthos da iminência da morte, gerando, como veremos, a urgência da virtude ${ }^{17}$.

Ao evocar essa expectativa, certas características psicológicas (páthe ${ }^{18}$ são evocadas e ganha-se uma perspectiva da iminência da necessidade da virtude para se contrabalançar a iminência da morte. Assim, a virtude

\footnotetext{
${ }^{16}$ Apesar de dramáticamente o aspecto da iminência ser fundamental no diálogo Fédon, já que obviamente Sócrates está prestes a morrer, argumentativamente a urgência para se ser virtuoso não é algo tão ressaltado no diálogo. Talvez isso se dê exatamente pelo fato de praticamente todo o diálogo se ocupar com a prova da eternidade da alma, e a urgência perante a morte se torne algo complexa no diálogo. Se torna mais interessante, nesta perspectiva, perceber que o pathos da urgência da virtude surge para o monasticismo muito vinculado à espera do dia do juízo final. Assim, não se trata tanto de uma urgência provocada pela ideia de perda da vida que levamos agora, mas pela proximidade do julgamento desta vida e a consequente punição ou recompensa.

${ }^{17}$ Iminência é diferente de urgência. A urgência é a perspectiva psíquica que é gerada a partir de um fato prestes a acontecer.

${ }^{18}$ Estou pensando aqui algo conectado a um estado de ânimo, uma predisposição psíquica, que talvez fosse melhor traduzido para o grego como hexis e não como pathos. Pensando na psicologia estoica em que o pathos provém de um juízo sobre o mundo a nossa volta, acredito que o termo seja também adequado.
} 
se torna urgente e vence-se a procrastinação. Talvez possamos fazer uma relação entre a acídia e a procrastinação, e neste sentido fundamentaríamos, como veremos, a relação próxima entre exercício da morte e a vitória sobre a acídia no Praktikós $29^{19}$.

No entanto, vale sublinhar, o contexto do escrito de Atanásio é outro (não uma técnica específica para vencer um demônio específico): trata-se, aqui, de técnicas para se superar a sensação de que já se fez muito na sua ascese passada. Este exercício da imaginação da iminência da morte insiste na necessidade de se iniciar sempre na ascese como se fosse um início do zero. O tema principal do capítulo anterior, o 18, por exemplo, está relacionado ao esforço contínuo e renovado para a ascese. Assim, o 19 apresenta o exercício da lembrança da iminência da morte como um auxílio para este renovar-se diário do esforço da ascese. Temos um tema muito interessante já presente aqui em Atanásio que é exercitar a perspectiva da vida com uma temporalidade dupla e invertida: vivemos hoje o primeiro e o último dia da ascese. Esforçamo-nos na ascese como se hoje fosse o primeiro dia a iniciarmos a vida de monge e ao mesmo tempo como se fosse a último, e morreríamos hoje ao anoitecer. ${ }^{20}$

No entanto, o que importa em nossa exposição é a descrição propriamente do que é o exercício da morte neste texto. A expressão fundamental aqui é ộs kath'heméran prosdokộntes apothnéskein, "como se esperassem (tivessem a expectativa de) morrer a cada dia". Trata-se de um exercício da imaginação que solicita um tipo de expectativa (prosdokô̂ntes), um exercício de expectativa da urgência, poderíamos dizer. Não há correlato a isso no Fédon, pelo menos no que eu pude constatar. Claro que no Fédon temos elementos post mortem e escatológicos, mas nas passagens de descrição do exercício da morte, temos mais claramente, como já vimos, uma exposição de práticas vinculados ao corpo e às posses e aspectos epistemológicos vinculados ao relacionamento entre alma e corpo. Em verdade, no Fédon, o lugar deste pathos da iminência está vinculado ao cenário geral, o enredo, construído no diálogo, pois se trata, obviamente, dos instantes anteriores à morte de Sócrates. No entanto, não há um imperativo de se experimentar a iminência da morte nas passagens centrais sobre o exercício da morte. Mesmo assim, aqui em Atanásio a exigência da urgência para a virtude é muito mais explícita.

\footnotetext{
${ }^{19}$ Veremos mais abaixo que neste capítulo 29 do Praktikós o exercício da morte é claramente identificado como um antídoto ao demônio da acídia.

${ }^{20}$ As virtudes insufladas pelo páthos da iminência da morte listadas por Atanásio nesta passagem se relacionam tanto (1) ao apego aos bens materiais, como também a (2) uma ética interpessoal (perdão, não ter rancor) e como também (3) ao desejo (impuro). Poderíamos, talvez, afirmar que o exercício da morte em Antão estaria se contrapondo a três tipos de demônios: a avareza, a raiva e a luxuria, mas isto não é explícito no texto e ao fazer isso trago a demonologia de Evagrio para a obra de Atanásio.
} 


\section{O exercicio da morte no Praktikós de Evágrio Pôntico}

Este artigo é fruto de uma pesquisa mais ampla que levou em conta diversas entradas tanto em Evágrio quanto nos Apoftegmas em que o exercício da morte é de alguma maneira referido. Como forma madura da pesquisa, apresento aqui apenas a análise de dois capítulos (kephalaí, isto é, máximas) do Praktikós de Evágrio, texto vinculado à parte de sua obra sobre ascese, isto é, não àquela parte vinculada à mística ou gnose. Vale indicar que toda a obra de Evágrio é apresentada como contendo essas duas grandes partes, uma vinculada a praktiké, isto é, à ascese propriamente dita, primeira etapa do progresso espiritual, e outra vinculada a gnostiké segunda etapa, em que há uma gnose de Deus, certo tipo de conhecimento da divindade cristã com suas especificidades evagrianas (trindade, ausência das representações, vinculada ao agápe amor, etc).

No entanto, não se deve separar estas duas instâncias como se fossem excludentes, pelo contrário, elas são intimamente vinculadas. Deve-se ressaltar que o âmbito gnóstico está presente desde o início das práticas ascéticas, e a praktiké, com suas extenuantes abstinências, não termina ao se alcançar alguma dose de conhecimento divino. Aliás, tal conhecimento divino perfeito só é alcançado depois da morte, portanto o cuidado com os demônios e as tentações se torna necessário durante toda a vida.

Dentre os textos de Evágrio que analisaremos, o exercício da morte é apresentado como um exercício de imaginação. Nos dois capítulos extraídos do Praktikós indicados, trata-se de trazer à mente, voluntariamente, aspectos da morte para a produção de virtudes e características que o possibilitam a realizar a gnósis. O objetivo geral parece propiciar ao monge tanto motivos quanto força psíquica para exercer a ascese.

\subsection{O Praktikós 52}

Comecemos, pois, pelo texto ${ }^{21}$.

Por um lado, separar o corpo da alma, (pertence) somente Àquele que os uniu; por outro, separar a alma do corpo, (pertence) também àquele que se encaminha à virtude. Pois, os nossos pais nomeiam a anacorese de exercício da morte e a fuga do corpo. (Tradução do autor)

Temos nesta passagem o exercício da morte estreitamente vinculado ao Fédon, em que se trata não tanto de se lembrar da morte diariamente, como vimos em Antão e veremos mais adiante, mas de praticar a morte,

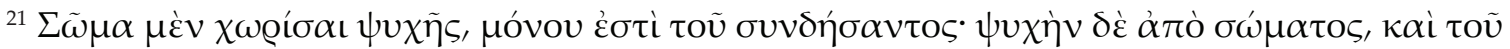

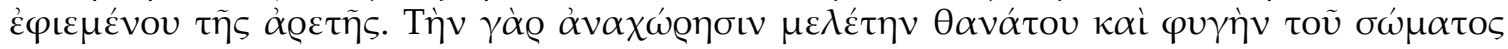

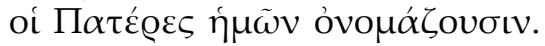


exercer o acontecimento da morte propositadamente. Este acontecimento como é descrito aqui e no Fédon é a separação da alma retirando-a do corpo e podemos fazer uma comparação direta indicando pelo menos os aspectos mais práticos da ascese presentes no ascetismo monástico em geral e no Fédon: procurar ocupar a alma consigo mesma e não preocupar-se com o corpo, afastar sua atenção e seu cuidado primordial das atividades corpóreas.

Primeiramente, vale algumas palavras sobre a separação reversa, a de se retirar o corpo da alma. Encontramos no 52 do Praktikós uma distinção interessante entre separar o corpo da alma e separar a alma do corpo. Apesar de esse linguajar não estar presente no Fédon, a interdição ao suicídio presente em $61 \mathrm{c}-\mathrm{d}^{22}$ parece ser o que baliza a argumentação. Nas notas da edição de Guillaumont ${ }^{23}$ a este capítulo, a interdição ao suicídio é indicada no Kephalaia Gnóstiká IV 76 e 83, mas a referência ao excesso da ascese presente no capítulo 29 que analisaremos em breve também é comentada. Guillaumont também cita Refoulé24 que afirma ser a base para Evágrio o livro de Porfírio chamado Sententiae ou Aphormai pros tà noẹtá 8 e $9^{25}$. Assim, podemos ver em Porfírio já o início de tradição com esse jogo de palavras.

De toda forma, neste capítulo 52 do Praktikós, o exercício da morte será identificado com o termo central para a ascese monástica, a anachóresis. Isto equivale dizer que este exercício é de alguma forma um representante da ascese enquanto tal, da prática anacorética como um todo, e precisamos descrever com maior detalhe que prática é esta. Se por um lado o termo anachóressis no monasticismo remete para uma fuga do mundo, implicando um retiro do mundo dito civilizado, da cidade propriamente, para o deserto, para o isolamento, o termo já possuía aspectos espirituais há algum tempo. Festugière em seu livro Personal Religion among the Greeks ${ }^{26}$ tem um

\footnotetext{
${ }^{22}$ A expressão principal para suicídio no Fédon não é afastar o corpo da alma, sộma chorísai psykhêes, mas sim biásetai hautón, fazer violência contra si mesmo. A expressão utilizada pelo Evágrio parece ser uma transposição da expressão típica do Fédon que é separar a alma do corpo, khoris men apo tes psyches apallagen.

${ }^{23}$ EVAGRIUS. Praktikós. Traité Pratique ou Le Moine. Traduzido e comentado por Antoine e Claire Guillaumont. Sources Chrétiennes n. 170 e 171. Paris: CERF, 1971.

${ }^{24}$ REFOULÉ, F. "Évagre fut-il origéniste?" Revue des sciences pihlosophiques et théologiques. Vol. 47 no 3 Julho, 1963, p. 398-402, p. 402, nota 13.

${ }^{25}$ Na tradução de Davidson, 1869, "That which nature binds, nature also dissolves: and that which the soul binds, the soul likewise dissolves. Nature, indeed, bound the body to the soul; but the soul binds herself to the body. Nature, therefore, liberates the body from the soul; but the soul liberates herself from the body. 9. Hence there is a twofold death; the one, indeed, universally known, in which the body is liberated from the soul; but the other peculiar to philosophers, in which the soul is liberated from the body. Nor does the one entirely follow the other. »

${ }^{26}$ FESTUGIÈRE, Andre-Jean. Personal Religion Among the Greeks. Los Angeles : University of California Press, 1954, capítulo IV "The Inclination to retirement".
} 
iluminador capítulo (apesar de pequeno) sobre a inclinação pelo retiro. Ele analisa o termo anachóresis em diversos autores antigos e defende que muito antes do movimento monástico cristão, o termo já tinha aspectos espirituais ${ }^{27}$. "O retirar-se do mundo (anachóresis) leva, por sua vez, ao retirar-se para dentro de si mesmo" 28 . Trata-se de uma fuga do mundo operada de modo interno, realizada internamente e não necessariamente exigindo um deslocamento físico. Festugière defende que este retirar-se para dentro de si está intimamente conectado com o exercício de prestar atenção a si (prosokhé heautôii) e já podemos ver isso em Platão. Temos a expressão já utilizada na famosa passagem do Banquete em que Sócrates se retira à porta da casa de Agatão. Sua atividade é "prestar atenção em seu próprio pensamento" 29 e o escravo diz que "ele mesmo se retirou" 30 para ao lado da porta de entrada. Aristodemo diz que é hábito de Sócrates agir desta maneira, de tempos em tempos ele "se ausenta onde quer que esteja" ${ }^{31}$. Não menos relevante é a utilização no próprio Fédon, em que o termo aparece vinculado a retirar-se das impressões do sentido ${ }^{32}$. Assim, vemos que já em Platão, há uso para o termo não no sentido literal remetendo a locomoção espacial, mas a um processo interior de afastamento do mundo sensível.

Para fazermos a transposição do termo anachóressis para a ascese enquanto tal no mundo monástico podemos recorrer ao apoftegma III, $5^{33}$. Há ali uma transposição do recolhimeto praticado pelo monge dentro da cela para uma atitude psíquica geral que pode ser realizada em qualquer lugar. Lembrando-se das diretrizes básicas da vida anacorética, o monge pode praticar o seu "sentar em sua cela" em qualquer lugar que esteja, basta que tenha em mente os seus princípios fundamentais. Assim, o sentar em sua cela é antes de tudo um ato interno, e se este ato não for realizado, mesmo que se sente efetivamente na cela, não haverá a prática da ascese. Como se diz, os padres do deserto eram exímios conhecedores das coisas do coração, e a percepção de que os atos exteriores devem ser acompanhados por atos interiores é muito frequente nos textos ascéticos monásticos. Este ato interno, que é um afastamento de tudo que é criado, é chamado aqui de anachóresis e exercício da morte.

\footnotetext{
${ }^{27}$ Festugière começa por trabalhar o termo vinculado a atividades políticas, relacionadas à retirar-se da vida pública. Mas alguns filósofos já haviam trabalhado esse tema, especialmente Plotino e Orígenes.

${ }^{28}$ anakhoreîn eis heautón, Festugière, 1954, p. 57, tradução livre.

${ }^{29}$ Heautôi pộs proséxonta tòn noûn. Symp. 174d.

${ }^{30}$ Sokrátẹs hoûtos anachorésas 175a.

${ }^{31}$ Eníote apostàs hópoi án tykhei héstęen 175b.

32 83a ek toûton [tộn aistheseôn $n$ ] anachoreîn.

${ }^{33}$ Colocarei aqui apenas a parte inicial e final: “[...] Veja, então, para que não se esqueça da memória destes [preceitos], estando tanto dentro ou fora da sua cela. Não desvie seu espírito para que, pelo menos por meio destes, proteja-se dos pensamentos nocivos e impuros."
} 


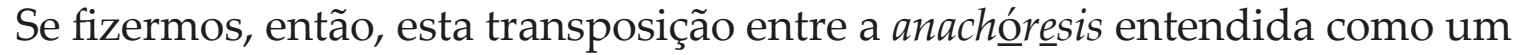
movimento físico para ela ser entendida como um movimento psíquico, o movimento de saída da cidade, de fuga do mundo, se torna o movimento geral da alma de fuga do corpo. O corpo aqui é um correlato da cidade, do mundo (kosmos), e a phýgẹn tôิ sómatos é um correlato da fuga mundi. Temos que o ato de "retirar-se" se torna o ato por excelência da ascese, deste recolher-se sobre si mesmo, concentrar-se sobre os movimentos de seu espírito, buscando o que vive em si mesmo de acordo ou não com Deus.

Vale ressaltar o trecho do livro em que o capítulo 52 se encontra. Na medida em que estamos em uma passagem do Praktikós $^{34}$ que lida com a apátheia, isto é, a tranquilidade do espirito pela ausência de paixões/emoções, o ato de fugir do corpo e recolher-se sobre si mesmo concede à alma a possibilidade de superar as páthe, as emoções. Assim, esta anachór $\underline{\text { esis }}$ pode ser entendida como um afastar-se das emoções que tem um vínculo forte com o querer preservar o corpo ${ }^{35}$.

Apenas mais um ponto importante aqui. Vimos já em Santo Antão o imperativo de sempre se ter presente o estado de espírito do início da ascese, isto é, que o monge, não importa o quanto já tenha praticado, não deve se entregar a calcular o "quanto" de ascese já praticou anteriormente, mas encarar o dia de hoje como um novo começo. Na medida em que o movimento da anachóressis é o primeiro movimento ascético, isto é, deixar a casa e a cidade onde nasceu e rumar para o deserto para começar a praticar a ascese, a partir deste capítulo do Praktikós, vemos toda a prática ascética como sendo algo que se inicia agora. Assim, sempre novamente estamos praticando o "sair da cidade e ir para o deserto" que configura o movimento inicial monástico como anachóressis.

\subsection{Praktikós 29}

Vamos, agora, analisar o capítulo 29 do Praktikós ${ }^{36}$.

Dizia, pois, o santo e muito instruído na prática, nosso professor: é necessário de tal modo o monge se exercitar como se fosse morrer no dia seguinte, e novamente, de tal modo cuidar do corpo como se fosse viver muitos anos.

\footnotetext{
${ }^{34}$ De modo geral, o Praktikós se divide, além de uma pequena introdução (1-5) e uns apoftegmas finais (91-100) em duas grandes partes: uma sobre os pensamentos, paixões e demônios (6-53), vistos como sinônimos, e outra sobre apátheia (54-90), que é o objetivo geral da parte praktikós de seu sistema.

${ }^{35}$ Ver o artigo PINHEIRO, M. A ascese das emoções em Epicteto e em Evágrio Pontico. In Prometheus, v. 11, n. 27, maio - agosto de 2018. Páthos pode ser um outro nome para demônio.

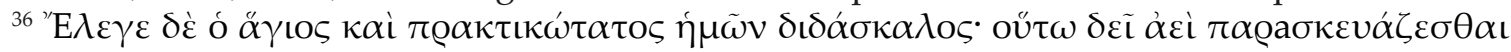

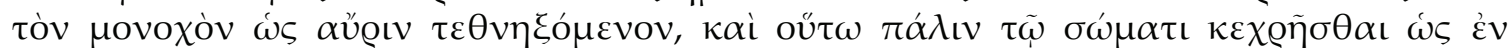

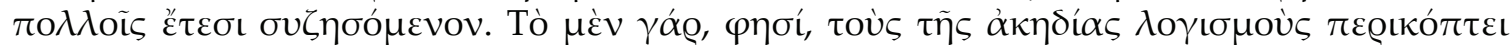

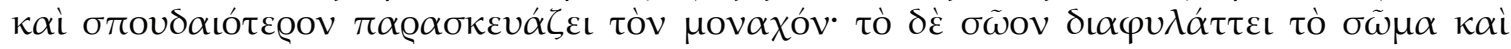

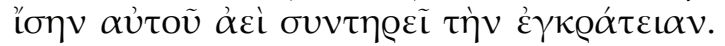


Pois, por um lado, dizia, <isso> erradica os pensamentos de acídia e exercita o monge a tornar-se mais diligente; por outro, então, guarda saudável o corpo e preserva sempre igual sua autocontenção. (Tradução do autor)

Esta passagem está claramente inserida nos exercícios que compõem a luta contra o demônio da acídia ${ }^{37}$. Temos claramente duas partes do texto, após a indicação do mestre muito prático ${ }^{38}$ : numa primeira, indica-se um imperativo na forma de um oxímoro (viver morrendo e morrer vivendo) para depois se explicar os benefícios de cada um dos polos de oposição. De modo semelhante ao 52, tem-se uma oposição de formas retóricas, invertendo no mesmo conselho relações opostas a ideias opostas. A utilização dupla do como se, hós em grego, indica o exercício de imaginação: deve-se fazer tal coisa como se tal outra coisa fosse realizar-se. Assim, temos aqui uma recomendação para se ter em mente uma ideia complexa e contraditória e realizar atividades de acordo com ela.

Trata-se de um imperativo duplo para a vida do asceta que, aparentando contradição, incentiva um meio termo em sua ascese: por um lado, exercitar-se como se fosse morrer iminentemente, por outro lado, usar o corpo como se fosse continuar a viver por muito tempo. A utilização da ideia contraditória de viver morrendo e morrer vivendo está presente aqui de alguma maneira, e essa oposição parece temperar os excessos da ascese, por um lado, e impulsionar o monge na prática extenuante da ascese, por outro.

Assim, retomando o texto por partes, o primeiro termo, paraskeuázo é quase um sinônimo para a ascese em geral: trata-se de se preparar, se exercitar, treinar e não há propriamente um objeto a ser exercitado: ao realizar todo e qualquer exercício, deve-se ter isso em mente, indicando que a ascese como um todo deve ser praticada com a imaginação da iminência da morte. Pelo fato de a morte estar tão próxima (aúrion), o monge não tem nada a perder, deve jogar-se todo no aqui e agora ${ }^{39}$ e intensificar ao máximo a sua ascese na tentativa de aproximar-se ao máximo da vida santa, da salvação. Se há algum momento a ser usufruído são os poucos que restam até a morte iminente. Note-se que não estamos ainda para além da praktiké, além do momento do exercitar da ascese que é a parte ainda inicial do monge. Neste sentido, acredito que podemos pensar o exercício da ascese produzindo um tipo de páthos apropriado para a intensificação da ascese e dos seus exercícios. Assim, todo o páthos da urgência de que falávamos está aqui presente novamente. Fazer ascese monástica é viver de modo urgente.

Por outro lado, em contraposição ao imperativo do "viver morrendo", há o "morre vivendo", no sentido de que ao se praticar a ascese há uma

\footnotetext{
${ }^{37}$ Sobre as partes do Praktikós e sua divisão, ver nota 34.

${ }^{38}$ Sobre quem seria esse mestre, Guillaumont indica Macário, o Grande em sua nota a essa passagem.

${ }^{39}$ Sobre a relação dos exercícios da morte e do carpe diem, ver o artigo "Exercices spirituels antiques et "philosophie chrétienne", in HADOT, Pierre. Exercises spirituelles et philosophie antique. Paris: Institut d'Etudes Augustiniennes, 1986.
} 
utilização ( $k$ hrêssthai) do corpo que deve cuidar minimamente dele. Aparece novamente, com uma roupagem diferente, a interdição ao suicídio que vimos tanto no Fédon quanto no Praktikós 52, agora na forma da interdição a uma ascese exagerada. Há que se temperar as imposições excessivas, muitas vezes fruto da vaidade.

Não se trata de uma reta de chegada em que o corredor se esforça tanto que ao final termina desfalecido e morto, como na corrida até Maratona, mas de um saber dosar a ascese. O imperativo de se saber dosar a ascese é constante nos textos ascéticos deste período e muitos deles trabalham os perigos do demônio da vaidade, que cresce junto com as vitórias do monge: quanto mais se vence da gula, da luxuria, da avareza, mais a vaidade pode tomar posse do monge. Assim, a humildade é a guardiã das práticas excessivas da ascese.

Essa duplicidade do exercício da morte também tem ressonâncias nas escrituras. O locus classicus é Romanos 6, que aparece em um apoftegma ${ }^{40}$ de Antão. Na epistola paulina, temos a expressão muito famosa de se estar morto para o pecado e vivo para Deus. Toda uma oposição construída com oxímoros é apresentada neste capítulo de Romanos, o batismo, que faz o cristão nascer em nova vida é um batismo na morte de Cristo ${ }^{41}$.

Vale ressaltar, ainda, que tanto aqui como no 52 visto anteriormente, não há propriamente uma imaginação do post-mortem nem muito menos de uma escatologia apocalíptica como se pode ver em outros textos vinculados a Evágrio ${ }^{42}$. Temos neste capítulo 29, no que concerne ao exercício da morte, o exercício imaginativo de seu aspecto iminente, incentivando o pathos da urgência com o fim de fortalecer o monge nos desafios da ascese.

Como forma de resumo, poderíamos dizer o seguinte. Por um lado, a parte mais propriamente voltada para a imaginação da iminência da morte remete para a mutilação da acídia, que é o demônio vinculado à preguiça. Assim, frente à urgência dos poucos instantes de vida, a acídia perde a força de convencimento da alma, e o monge ganha da procrastinação. Por outro lado, o lembrar-se de que se vai conviver durante muitos anos com o próprio corpo, o protege de excessos e conserva de modo equilibrado a contenção tão importante da ascese.

Por fim, algumas palavras sobre a expressão páthos para descrever o estado de espirito promovido por esse exercício. Tento aqui uma defesa do modo como eu nomeio essa expectativa da iminência da morte como sendo algo

\footnotetext{
${ }^{40}$ Ver por exemplo, o apoftegma III, 1 ou Antão 33 em que o santo solicita que se pense nas palavras de Paulo de Romanos 6.

${ }^{41}$ Nekroùs mèn einai tê hamartía, zontas dè tọi theoi.

${ }^{42}$ Ver especialmente os apoftegmas III, 2 e III,5. Nestes apoftegmas, há um claro exercício de imaginação relacionado tanto a aspectos da suposta vida após a morte quanto a aspectos apocalípticos.
} 
da ordem do páthos ${ }^{43}$. O medo gerado pela expectativa de punições no post-mortem é considerado ainda um páthos, apesar de ser um tal que pode ajudar na execução das atividades extenuantes da praktiké. Assim como o monge joga um demônio contra o outro, como no caso da oposição entre a porneía (fornicação) e a kenodoxía (vaidade), também o medo da punição, mesmo sendo da ordem da ignorância, pode ser propício da tensão necessária para a ascese. Explico-me. Por vezes, Evágrio aponta o conflito entre dois pensamentos/demônios, o da fornicação e o da vaidade, sendo eles mutuamente excludentes. Assim, o monge pode se utilizar de um para se livrar do outro, mesmo que seja ainda de modo temporário, pois o melhor modo de se livrar de um demônio não é utilizando outro, mas pela própria liberdade de todos. Neste sentido, é possível utilizar elementos de realidades vinculados a níveis da ignorância humana para combatê-la.

Da mesma forma, acredito que esse páthos da expectativa não é propriamente algo da ordem da sabedoria ou da apátheia (ausência de paixões, objetivo final de toda praktiké), mas fruto ainda da ignorância e ainda algo que se pode qualificar como páthos. Mesmo assim, ele pode ser saudável, pode propiciar um estado de espirito produtivo para a ascese ${ }^{44}$.

\section{Conclusões}

Em uma visão geral do que é apresentado no Praktikós vinculado ao exercício da morte, temos dois aspectos centrais: 1. Toda a prática ascética, apresentada como anachóressis, de alguma forma é um retirar a alma do corpo, uma fuga do corpo, que pode ser entendida como um desprezar

\footnotetext{
${ }^{43}$ Agradeço aqui ao parecerista da presente revista pela leitura atenciosa e pelos argumentos que enriqueceram minha leitura sobre Evágrio. Ele me indicou tanto bibliografias relevantes quanto pontos interessantes sobre a obra de Evágrio como um todo que contribuíram para minha pesquisa. Os próximos parágrafos são uma tentativa de defender, contra alguns de seus argumentos, que o exercício da morte em Evágrio seja realmente produtora disso que chamo de páthos da iminência da morte.

${ }^{44}$ Ilaria Ramelli, em sua introdução ao Kephalaila Gnóstiká de Evágrio, diz o seguinte: “Once again like Origen, Evagrius reveals a deeply rooted "pastoral" concern in respect to the divulgation of the doctrine of universal restoration, especially among spiritually immature people, those who do good out of fear and not for love. It is better for such people to believe threats of eternal punishment, and thereby keep their fear, since this is what prevents them from sinning (only in the eventual apokatastasis will love prevent everyone from sinning).

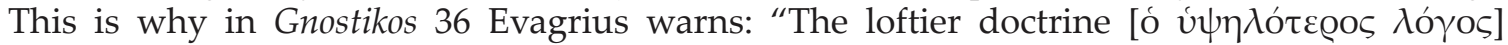
concerning the Judgment should be kept undisclosed to secular people and young people." Secular and Young people are the most spiritually immature, who need to believe in a material punishment, and that eternal, whereas the torment of the rational soul will consist in ignorance (ibid.), and this will not be eternal, since ignorance, according to Evagrius, will ultimately vanish, as well as evil will. [...] Love and virtue, and not fear, should urge people to do good-and virtue is primarily love and mercy, which are also the main features of God, the model of all virtues (ibid. 75)."
} 
as demandas corpóreas. O exercício da morte é visto como uma retirada da atenção do mundo sensível/corpóreo e um processo de conversão desta atenção para o mundo espiritual/divino. A interdição ao suicídio e aos excessos da ascese aparecem vinculados a este primeiro aspecto; 2 . Há um exercício da imaginação vinculado à produção no monge de um páthos da urgência, em que a lembrança da morte e a projeção de sua iminência produziria uma urgência para a vida virtuosa.

Por outro lado, retomando o que foi apresentado sobre o Fédon, dizíamos que ali três seriam os aspectos do exercício da morte: 1 . o aspecto ascético propriamente dito, de afastamento dos prazeres e dos cuidados corpóreos; 2. a produção de virtude a partir de uma purificação dos vínculos com o corpóreo; 3. a geração de uma epistéme especial, em que há um tornar-se semelhante entre o sujeito que conhece (agora purificado a partir da ascese) e o objeto conhecido, as puras formas.

Assim, fazendo a comparação entre os textos, percebemos muito mais traços dos dois primeiros aspectos do Fédon do que do terceiro. Nos textos de Evágrio analisados, percebemos que o terceiro aspecto do Fédon tem pouca relação com o monge nesta etapa da aprendizagem. Chama a atenção o fato de o teor epistêmico do Fédon não se apresentar nos textos monásticos analisados, incluindo, neste caso, o texto sobre Antão.

No entanto, uma ressalva importante é necessária. O objetivo final, o telos, de toda a praktiké é a gnósis, isto é, o conhecimento de Deus. Claro é que estas duas instâncias não podem ser separadas como se nenhum aspecto de uma esteja implicado na outra. Assim, toda evolução na ascese implica algum grau de gnose, apesar de haver sim algum tipo de transformação entre aquele que é apenas um aprendiz para aquele que já é mais experiente na ascese. Ao apontar para o fato de que não há um discurso epistêmico no tratamento do exercício da morte não quero dizer que a gnose própria da vida monástica esteja totalmente excluída deste exercício. O que quero pontuar é que no desenvolvimento explícito deste exercício no Fédon, as questões epistêmicas são centrais, são explícitas, o que não é o caso dos textos de Evágrio analisados. No entanto, vale sublinhar, novamente, que as questões relativas a gnose estão vinculadas à toda a ascese monástica na medida em que o conhecimento tanto da natureza como reflexo das esferas superiores, quanto do próprio conhecimento de Deus estão de alguma forma presente na ascese mesmo que na forma de um télos, um objetivo final.

Assim, pode-se perceber que o exercício da morte no Praktikós não se mostra como um exercício intelectual, com o objetivo de se alcançar um conhecimento específico, vinculado às coisas em si (formas), como no Fédon. Trata-se de um auxílio à ascese típica monástica em que o lembrar-se da morte buscando sua iminência coloca o monge no páthos da urgência, 
solicitando dele maior empenho na ascese. Vinculado a este páthos da urgência, a recomendação de uma certa dosagem do impulso ascético é realçado lembrando a proibição ao suicídio.

\section{Bibliografia}

ANONIMO. The sayings of the desert fathers. The alphabetical collection. Trad. e notas : Benedicta Ward. Kalamazoo : Cistercian Publications, 1975.

ANONIMO. Les Apophtegmes des Pères. Collection systematique. Trad. e notas Jean-Claude Guy, Paris: CERF, 1993.

ATANASIO. A vida de Santo Antão; etc. São Paulo: Paulus, 2002. . Vie d'Antoine. Paris: Cef, 1994.

. A vida de Santo Antão. Tradução e notas de Bruno Gripp. Rio de Janeiro : Paideusis, 2019

BALTHASAR, Hans Urs von. "The Metaphysics and Mystical Theology of Evagrius", Monastic Studies, 3, 183-95, 1965.

BERNSTEIN, Alan. The formation of Hell: Death and retribution in the Ancient and early Christian Worlds. London : Routledge, 1993.

CASIDAY, A. Reconstructing the theology of Evagrius Ponticus. Cambridge: Cambridge University Press, 2013

CLARK-SOLES, Jaime. Death and the afterlife in the New Testament. New York : T\&T Clark, 2006.

DIETZ, M. Wandering Monks, Virgins and Pilgrims. Ascetic travel in mediterranean World, 300-800. Philadelphia: Pensilvania State University, 2005.

DODDS, E. R. Pagan and Christian in an Age of Anxiety. some aspects of religious experience from Marcus Aurelius to Constantin. Cambridge: Cambridge University Press, 1968.

EVAGRIUS. Praktikós. Traité Pratique ou Le Moine. Traduzido e comentado por Antoine e Claire Guillaumont. Sources Chrétiennes n. 170 e 171. Paris: CERF, 1971

. The Greek Ascetic Corpus. Traduzido e Organizado por SINKEWICZ, R.

E. Oxford: Oxford University Press, 2003.

. Evagrius Ponticus. Traduzido e Organizado por CASSIDAY, A. M. New York: Routledge, 2006.

Kephalaia Gnostiká. Traduzido e comentado por RAMELLI, I. Atlanta: SBL Press, 2015.

FESTUGIÈRE, Andre-Jean. Personal Religion Among the Greeks. Los Angeles: University of California Press, 1954.

GUILLAUMONT, A. «Un Philosophe au Désert: Évagre le Pontique ». In : Revue de l'histoire des religions tome 181, n¹, 1972. pp. 29-56. 

. Études de la spiritualité chrétienne. Paris: Abbaye de Bellefontaine, 1996. . Les Kephalia Gnostika chez Evagrius le Pontique. Paris: Seuil, 1962.

HADOT, Pierre. Exercices spirituelles et philosophie antique. Paris: Institut d'Etudes Augustiniennes, 1986.

HOVEN, R. Stoicisme et Stoiciens face au problème de l'au-delà. Paris: Belles Lettres, 1971. MARAVAL, P. "Le monaschisme oriental". In : PIETRI, C. \& PIETRI, P. Histoire du christianisme: des origines à nos jours. Naissance d'une chrétienté. Vol 2. Paris : Desclée, 1995.

. « D'Antoine à Martin : aux origines du monachisme occidental ». In: Vita Latina, $\mathrm{N}^{\circ} 172,2005$. pp. 72-82.

PINHEIRO, M. A ascese das emoções em Epicteto e em Evágrio Pontico. In Prometheus, v. 11, n. 27, maio - agosto de 2018.

PORFIRIO. "The Sentences of Porphyry the philosopher » Tradução de Thos Davidson In: the Journal of Speculative Philosophy, vol. 3, 1869.

REFOULÉ, F. «Évagre fut-il origéniste ? "Revue des Sciences philosophiques et théologiques , 47, 1963.

REGNAULT, L. The day to day life of the desert fathers in the fourth century Egypt. Massachusetts: St. Bede's Publication, 1999.

WIMBUSH, Vincent. \& VALANTASIS, Richard (eds.). Asceticism. Oxford: Oxford University Press, 1996.

WORTLEY, John. "How the Desert Fathers „Meditated"," in : Greek, Roman, and Byzantine Studies 46, 315-328, 2006

ZECHER, J. L. " Death among the desert fathers : Evagrius and Theophilus in the sayings tradition » Sobornost 36: 1, 148-6, 2014.

. The role of death in the Ladder of Divine Ascent and the Greek ascetic tradition. Oxford : Oxford University Press, 2015.

Endereço do Autor:

R. Conde de Avelar 44 - Apto. 302

Laranjeiras

22245-030 Rio de Janeiro - RJ

neoplatonismo@gmail.com 